\title{
On the possibility of using lime dust for the production of building materials of forced carbonate hardening
}

\author{
Aleksandr Bakhtin $^{1 *}$, Nikolai Lyubomirskiy ${ }^{1}$, Sergey Fedorkin ${ }^{1}$, and Tamara Bakhtina ${ }^{1}$ \\ ${ }^{1}$ V.I. Vernadsky Crimean Federal University, 4 Academician Vernadsky Ave., Simferopol 295007, \\ Russian Federation
}

\begin{abstract}
The paper presents research on the development of building materials with low level of $\mathrm{CO}_{2}$ emissions based on technogenic recycled materials. The paper addresses the determination of optimal formulation and technological parameters of obtaining materials based on lime dust generated by mechanical deposition in cyclones and bag filters of shaft furnaces, as well as finely dispersed marble limestone with a fraction of up to $5 \mathrm{~mm}$. Studies have shown that it is possible to obtain carbonized material with compressive strength of more than $40 \mathrm{MPa}$ from this recycled material by forced carbonization used during three hours. Moreover, to obtain such numbers, the optimal content of lime dust in raw materials should be in the range of $35-40 \%$ wt. when the water content of the mixture is $6-7 \%$ wt. The carbonized material obtained with the indicated technological parameters will have an average density of 1.95-2.0 $\mathrm{g} / \mathrm{cm} 3$ and water absorption by weight of not more than $12 \%$.
\end{abstract}

\section{Introduction}

Since the middle of the last century, there has been significant economic growth in the developed countries of the world, associated with the development of industrial production, and, accordingly, with high consumption of natural resources. The growth of industrial production led to certain environmental problems, including problems with climate change caused by significant emissions of greenhouse gases into the atmosphere, especially $\mathrm{CO}_{2}$. The significance of these problems and, accordingly, the need to respond to them, directs the world economy to the search for a new development vector. It forged the appearance of the concept of a "low-carbon economy", in which the carbon footprint will be the main criterion for evaluating any human activity, especially technological. In particular, in EU programs, including 'A Roadmap for moving to a competitive low carbon economy in 2050' [1], priorities for reducing $\mathrm{CO}_{2}$ emissions were included in all sectors of industrial production. The leading target is ways to reduce industrial $\mathrm{CO}_{2}$ emissions as the main industrial gas is causing significant climate change on the planet. Such innovations are fixed at the legislative level in the countries of the EU, the USA, Canada, Australia, and

\footnotetext{
Corresponding author: aleserba@gmail.com
} 
China and, first of all, should stimulate the organization and conduct of research work to find ways to reduce carbon dioxide emissions without harming the economy of states. To achieve the identified priorities, the International Energy Agency has identified a list of industrial production, in which it is advisable to organize research work to reduce $\mathrm{CO}_{2}$ emissions. According to this list, one of the promising industries is the industry for the production of various building materials. The largest $\mathrm{CO}_{2}$ emission process in this industry is the production of Portland cement and various lime binders, which together account for up to $10 \%$ of technogenic $\mathrm{CO}_{2}$ emissions worldwide $(2.9-3.1$ Gt per year) $[2,3]$. Accordingly, the use of this technogenic $\mathrm{CO}_{2}$ in the technological cycle as a raw material component without reducing the main production is the most expedient and effective way to reduce the emission of carbon dioxide into the atmosphere. Fundamental and applied scientific research in this direction began at the beginning of the 21 st century [4-7] and came down to finding ways to reduce $\mathrm{CO}_{2}$ emissions in cement production or developing alternative binders to Portland cement. During this process researchers mainly studied the kinetics of the reaction of carbonization of clinker-forming minerals, $\mathrm{MgO}$-containing systems and the change in the structure and properties of the obtained carbonized material. The intensification of research in this direction is observed after the climate conference in Paris and the signing of the relevant agreement by most of the countries of the world. The ratification of the final document of the conference was carried out by 186 countries in a short time, which indicates that the world community understands the seriousness of the consequences if these problems are further ignored. The intensification of scientific research has shown that the building materials industry is a very promising sector of the economy in addressing the issue of reducing carbon dioxide emissions into the atmosphere [8-24].

Conducted researches have led to the formation of the concepts of "environmental construction" and "safe and comfortable living environment" as one of the most relevant global trends in the construction industry, making up the concept of "sustainable development". According to these scientific trends, the most significant distinguishing feature that enhances the environmental aspects of construction is the use of building materials and products with low $\mathrm{CO}_{2}$ emissions, manufactured using technologies whose principal feature is the absorption and binding of technogenic carbon dioxide into insoluble compounds (sequestration). As a result of these studies, researchers have identified types of raw materials $[9,10,15-21]$, including secondary $[11-14,22]$, which have significant potential for $\mathrm{CO}_{2}$ binding, developed scientific and technological foundations for the implementation of the results in industry [13-15, 22], as well as released pilot batches of building products hardened in an environment of high concentration of $\mathrm{CO}_{2}[13,15]$. Summarizing the results of the studies, it can be noted that the directions for reducing $\mathrm{CO}_{2}$ emissions in the building materials industry are identified; their high efficiency is justified, in terms of quantifying $\mathrm{CO}_{2}$ and obtaining a certain range of high-quality building products that harden due to forced carbonization. However, for the introduction of such technologies, for example, at existing enterprises producing the main product, it is necessary to conduct individual scientific research aimed at exploring the possibility of using recycled materials to organize the production of materials and products using forced carbonization.

In connection with the foregoing, the aim of this work is to study the possibility of using technogenic recycled materials, in particular lime dust and finely divided limestone, to obtain building materials with high physical and mechanical characteristics using forced carbonization. 


\section{Materials and methods}

Lime dust, which is mechanically deposited in cyclones and bag filters of shaft furnaces that burn limestone to produce quicklime, was used as the material for scientific research. Along with it finely dispersed marble-like limestone with a fraction of up to $5 \mathrm{~mm}$ was used which is formed during the crushing of the initial rock into a working fraction sent to the shaft furnace for firing. These materials are produced at enterprises producing quicklime and are mainly sent to dumps, since there is practically no demand for this recycled material. The lack of demand is explained by the low quality of these products, in particular, lime dust contains burnt $\mathrm{CaO}$ particles, and the amount of active calcium and magnesium oxides, as a rule, does not exceed $25-35 \%$.

Thus, the presence of harmful burnt particles in a complex with a low content of active $\mathrm{CaO}$ and $\mathrm{MgO}$ causes a lack of demand. Finely dispersed marble-like limestone also does not find wide application in the construction industry due to the high content of dust and clay particles in it. In these studies, various raw materials were prepared from these materials, and cylinder samples with a diameter and a height of $30 \mathrm{~mm}$ were prepared by semi-dry pressing, curing of which was carried out in the developed carbonization chamber [25] under conditions of a $35 \%$ concentration of $\mathrm{CO}_{2}$ for 3 hours.

The mineralogical composition was determined using the high-temperature synchronous analyzer STA 8000 from Perkin Elmer (USA) in the temperature range of $30-1000^{\circ} \mathrm{C}$ at a heating rate of $10^{\circ} \mathrm{C} / \mathrm{min}$, in a nitrogen atmosphere. The particle size of the investigated raw materials was determined using the HORIBA LA-960 laser analyzer (Japan). The qualitative course of the carbonization reaction was determined by applying a $1 \%$ phenolphthalein solution to the cleaved sample. The optimization of the composition of the raw material mixture to obtain prototypes of semi-dry pressing on the basis of the studied materials was carried out using statistical methods of mathematical design of the experiment. Processing of the obtained experimental data was carried out using the StatSoft STATISTICA software package. As a result of processing the experimental data, ES (experimental statistical) models of each investigated parameter are formed, which are second-order equations of the following form:

$$
Y=b_{0}+\sum_{i=1}^{n} b_{i} z_{i}+\sum_{i ; l=1}^{n} b_{i l} z_{i} z_{l}+\sum b_{i i} z_{i}^{2}
$$

where $b_{o}, b_{i}, b_{i l}, b_{i i}$ are the correlation coefficients determined as a result of mathematical and statistical processing of experimental data; $z_{i}, z_{l}$ are the value of the varied formulation and technological factors. The mechanical characteristics of the prototypes were determined using an automatic test system, based on the MCC8 (Controls) control console. Before testing, the prototypes were dried to zero humidity in an oven at the temperature of $80^{\circ} \mathrm{C}$.

\section{Results and discussion}

Lime dust is a fine powder of light gray color. Laser analysis of particle size (Fig. 1) showed that this recycled material consists of particles ranging in size from 4 to 80 microns. Most of the particle size distribution is made up of particles ranging in size from 15 to 30 microns. The average geometric particle size is 15.5 microns. 


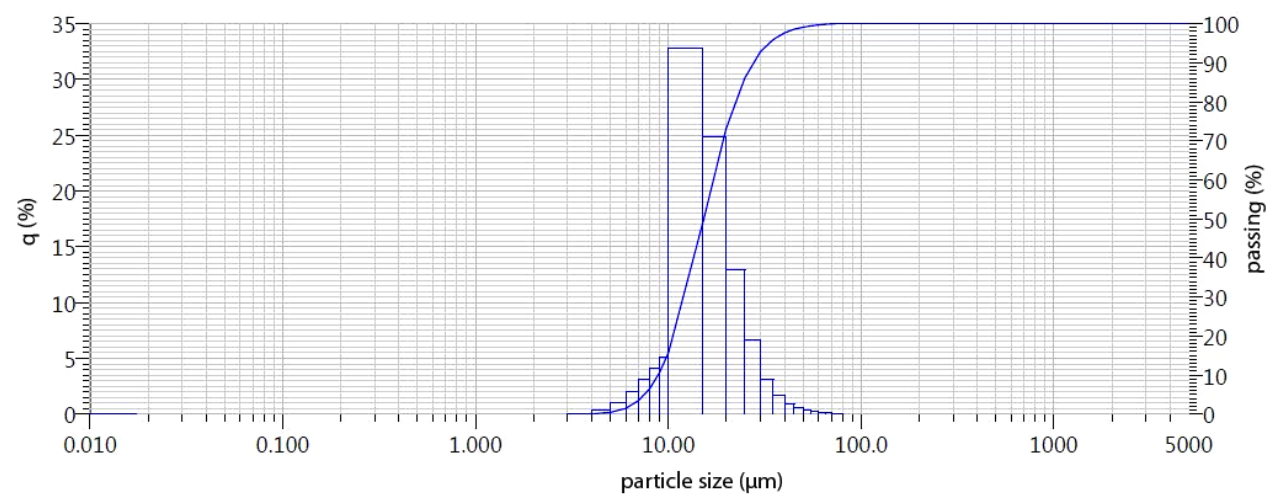

Fig. 1. Particle size distribution and differential curve of particle size distribution of lime dust.

An analysis of the mineralogical composition of calcareous dust was carried out using thermal analysis (see Fig. 2). Calculations of the quantitative content of the corresponding mineral phases were carried out according to equations. The calculation results are presented in table 1.

Table 1. Mineralogical composition of lime dust.

\begin{tabular}{|l|l|l|l|l|}
\hline $\begin{array}{l}\text { Losses in the } \\
\text { temperature } \\
\text { range } 450-\end{array}$ & $\begin{array}{l}\mathrm{Content} \text { of } \\
600\end{array}$ \\
$\mathrm{Ca}(\mathrm{OH})_{2} / \mathrm{CaO}$, & $\%$ & $\begin{array}{l}\text { Losses in the } \\
\text { temperature } \\
\text { range } 600- \\
1000{ }^{\circ} \mathrm{C}, \%\end{array}$ & $\begin{array}{l}\text { Content of } \\
\mathrm{CaCO}_{3} / \mathrm{CaO}, \%\end{array}$ & Impurities, \% \\
\hline 10.59 & $43.5 / 32.9$ & 21.65 & $49.2 / 27.6$ & up to 7.0 \\
\hline
\end{tabular}

Limestone dust in its mineralogical composition has almost $43-44 \%$ of $\mathrm{Ca}(\mathrm{OH})_{2}$. The number of particles of calcite is about $49-50 \%$ wt. Impurities do not exceed $7 \%$ wt. Also this raw material contains $2-3 \%$ wt. refractory burnt grains of $\mathrm{CaO}$. Due to the fineness of lime dust grains, the destructive effect of burnt particles on the properties of products made on its basis will be minimal. DTA curve of finely dispersed marble-like limestone with a fraction of up to $5 \mathrm{~mm}$ has one endothermic effect in the temperature range of $600-1000^{\circ} \mathrm{C}$, corresponding to the decomposition of calcium carbonate. The total weight loss in this range was $41.9 \% \mathrm{wt}$. Accordingly, the calcite content is $95.2 \% \mathrm{wt}$.

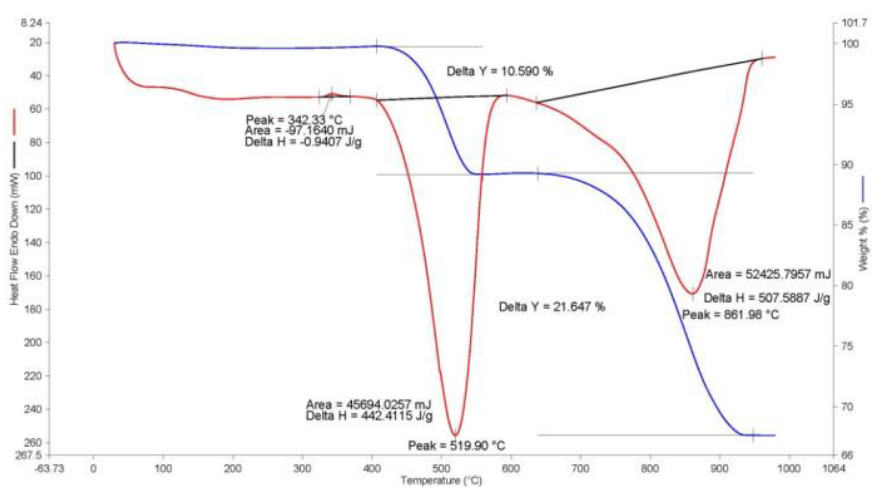

Fig. 2. TG-DTA curves of limestone dust.

To determine the optimal formulation and technological factors for the preparation of semi-dry pressed test samples based on the materials studied, and their subsequent forced carbonization, a rotatable central compositional plan was compiled. The following factors were taken as variable factors: the content of lime dust $\left(Z_{1}\right)$, the water content of the raw 
material mixture $\left(Z_{2}\right)$, and the pressing pressure of the experimental cylinder samples $\left(Z_{3}\right)$. The levels of variation of the studied factors are presented in table 2.

Table 2. Conditions for the experiment.

\begin{tabular}{|c|c|c|c|c|c|c|}
\hline \multirow{2}{*}{ Factor } & \multirow{2}{*}{$\begin{array}{c}\text { Measureme } \\
\text { nt units }\end{array}$} & \multicolumn{5}{|c|}{ Levels of variation } \\
\cline { 3 - 7 } & & -1.682 & -1 & 0 & +1 & +1.682 \\
\hline $\mathrm{Z}_{1}$ & $\%$ wt. & 13.18 & 20.0 & 30.0 & 40.0 & 46.82 \\
\hline $\mathrm{Z}_{2}$ & $\% \mathrm{wt}$. & 4.64 & 6.0 & 8.0 & 10.0 & 11.36 \\
\hline $\mathrm{Z}_{3}$ & $\mathrm{MPa}$ & 16.6 & 20.0 & 25.0 & 30.0 & 33.4 \\
\hline
\end{tabular}

Forced carbonization of the samples was carried out under normal conditions $(\sim 20-30$ ${ }^{\circ} \mathrm{C}$, atmospheric pressure). The concentration of $\mathrm{CO}_{2}$ in the carbonization chamber was $33-35 \%$. The carbonation time was constant and equaled 3 hours. The main parameters analyzed for carbonized prototypes were: compressive strength $\left(R_{c}\right)$, average density $(\rho)$, water absorption $\left(\mathrm{W}_{\mathrm{m}}\right)$, water resistance $\left(\mathrm{K}_{\mathrm{s}}\right)$. Analysis of experimental data (see table 3 ) showed that the properties of carbonized cylinder samples vary over a wide range depending on the varying technological factors.

Table 3. Planning matrix and experimental data of carbonized prototype cylinders.

\begin{tabular}{|c|c|c|c|c|c|c|c|c|c|c|}
\hline \multirow{2}{*}{$\begin{array}{c}\text { № } \\
\mathrm{g}\end{array}$} & \multicolumn{2}{|c|}{ Coded values of factors } & \multicolumn{3}{|c|}{$\begin{array}{c}\text { Natural values of } \\
\text { factors }\end{array}$} & \multicolumn{4}{|c|}{ Analyzed parameters } \\
\cline { 2 - 12 } & $\mathrm{Z}_{1}$ & $\mathrm{Z}_{2}$ & $\mathrm{Z}_{3}$ & $\begin{array}{c}\mathrm{Z}_{1}, \\
(\%)\end{array}$ & $\begin{array}{c}\mathrm{Z}_{2}, \\
(\%)\end{array}$ & $\begin{array}{c}\mathrm{Z}_{3}, \\
(\mathrm{MPa})\end{array}$ & $\begin{array}{c}\mathrm{R}_{\mathrm{c} .}, \\
(\mathrm{MPa})\end{array}$ & $\begin{array}{c}\rho, \\
\left(\mathrm{g} \cdot \mathrm{cm}^{-3}\right)\end{array}$ & $\mathrm{K}_{\mathrm{s}}$ & $\begin{array}{c}\mathrm{W}_{\mathrm{m}} \\
(\%)\end{array}$ \\
\hline 1 & -1 & -1 & -1 & 20.0 & 6.0 & 20.0 & 21.8 & 1.99 & 0.84 & 11.4 \\
\hline 2 & +1 & -1 & -1 & 40.0 & 6.0 & 20.0 & 30.9 & 1.82 & 0.74 & 15.5 \\
\hline 3 & -1 & +1 & -1 & 20.0 & 10.0 & 20.0 & 20.8 & 1.98 & 0.62 & 11.3 \\
\hline 4 & +1 & +1 & -1 & 40.0 & 10.0 & 20.0 & 32.9 & 1.98 & 0.77 & 13.9 \\
\hline 5 & -1 & -1 & +1 & 20.0 & 6.0 & 30.0 & 31.0 & 2.06 & 0.66 & 10.3 \\
\hline 6 & +1 & -1 & +1 & 40.0 & 6.0 & 30.0 & 43.8 & 1.90 & 0.69 & 13.3 \\
\hline 7 & -1 & +1 & +1 & 20.0 & 10.0 & 30.0 & 18.4 & 2.02 & 0.73 & 10.5 \\
\hline 8 & +1 & +1 & +1 & 40.0 & 10.0 & 30.0 & 28.5 & 1.91 & 0.73 & 13.1 \\
\hline 9 & -1.682 & 0 & 0 & 13.18 & 8.0 & 25.0 & 14.9 & 2.09 & 0.60 & 9.1 \\
\hline 10 & +1.682 & 0 & 0 & 46.82 & 8.0 & 25.0 & 41.0 & 1.80 & 0.68 & 15.6 \\
\hline 11 & 0 & -1.682 & 0 & 30.0 & 4.64 & 25.0 & 30.1 & 1.92 & 0.71 & 13.1 \\
\hline 12 & 0 & +1.682 & 0 & 30.0 & 11.36 & 25.0 & 12.9 & 1.92 & 0.71 & 12.8 \\
\hline 13 & 0 & 0 & -1.682 & 30.0 & 8.0 & 16.59 & 30.4 & 1.88 & 0.68 & 14.6 \\
\hline 14 & 0 & 0 & +1.682 & 30.0 & 8.0 & 33.41 & 39.6 & 1.98 & 0.69 & 11.7 \\
\hline 15 & 0 & 0 & 0 & 30.0 & 8.0 & 25.0 & 36.2 & 1.94 & 0.58 & 12.8 \\
\hline 16 & 0 & 0 & 0 & 30.0 & 8.0 & 25.0 & 36.0 & 1.94 & 0.60 & 12.9 \\
\hline 17 & 0 & 0 & 0 & 30.0 & 8.0 & 25.0 & 36.3 & 1.95 & 0.59 & 12.8 \\
\hline 18 & 0 & 0 & 0 & 30.0 & 8.0 & 25.0 & 35.8 & 1.93 & 0.60 & 12.7 \\
\hline
\end{tabular}


Analysis of the influence of the amount of lime dust in the compositions of raw mixes (see table 3) shows that with an increase in the content of this component from 20 to $40 \%$ wt. strength indicators of prototypes increase in average in 1.4-1.7 times. Moreover, due to the increase in the composition of the fine particles, the average density of the material decreases and, accordingly, the water absorption increases. It should be noted that an increase in the content of lime dust, despite an increase in the rate of water absorption, increases the water resistance of the samples. The increase in the initial water content of raw mixes from 6 to $10 \%$ wt. with the same other studied factors, reduces the strength of carbonized samples. Since limestone has a denser structure and correspondingly lower water absorption compared to lime dust, most of the water remains in the intergranular space, increases the water-lime ratio and, thereby, slows down the process of carbonation of lime dust. The degree of carbonation of the calcareous component in the experimental samples can be indirectly judged by the change in the size of the carbonized layer (Fig. 3). From the data presented in Fig. 3, it can be seen that the formation of a carbonate stone during the carbonate hardening of a calcareous binder begins from the surface of the samples, gradually moving deeper with a diffusion restriction of carbon dioxide. The degree of lime carbonization depends on all the studied formulation and technological factors. With increasing pressing pressure and the content of lime dust, the thickness of the carbonized layer in the test samples decreases. As the pressing pressure increases, the structure of the material becomes denser, which complicates the movement of gas through the pores of the material.
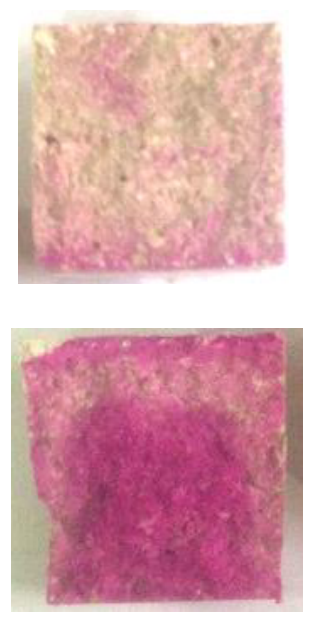

$\mathrm{Z}_{2}-6 \%$

$\mathrm{Z}_{3}-20 \mathrm{MPa}$

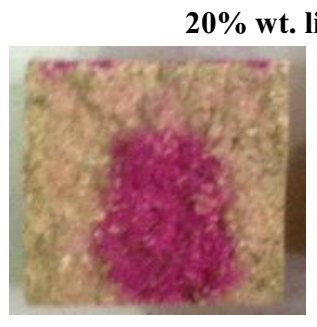

$40 \%$ wt. lime dust

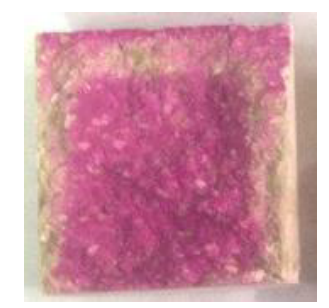

$Z_{2}-6 \%$

$\mathrm{Z}_{3}-30 \mathrm{MPa}$

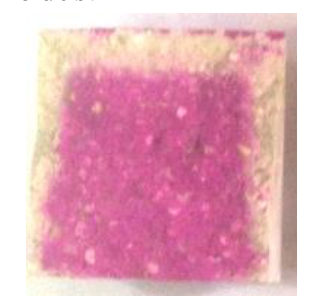

$\mathrm{Z}_{2}-\mathbf{1 0} \%$

$\mathrm{Z}_{3}-\mathbf{2 0} \mathrm{MPa}$
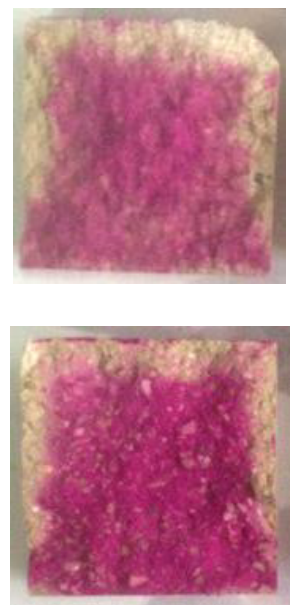

$\mathrm{Z}_{2}-\mathbf{1 0} \%$ $\mathrm{Z}_{3}-30 \mathrm{MPa}$

Fig. 3. The change in the thickness of the carbonized layer of the test samples obtained at the water content of the molding mixture $\left(Z_{2}\right) 6$ and $10 \%$ wt. and pressing pressure $\left(Z_{3}\right)$ of 20 and $30 \mathrm{MPa}$.

Adding of more lime dust, a finely divided component, leads to the formation of smaller pores and also complicates the diffusion of the gaseous medium through the pores in the bulk of the material. It is possible that the complete carbonization of the calcareous component in experimental samples with a content of $40 \%$ wt. needs more than 3 hours of forced carbonization, which were insufficiently accepted in the experiment. The analysis of the ES model of the main properties of the test samples showed that the most influential factors on the formation of the properties of carbonized samples in decreasing order of 
importance are: the content of lime dust $\left(Z_{1}\right)$, the water content of the raw material mixture $\left(Z_{2}\right)$, and the pressing pressure of the experimental cylinder samples $\left(Z_{3}\right)$. The equations obtained by statistical data processing (table. 3 ) are the following:

$$
\begin{gathered}
R_{c}=36.52+15.80 Z_{1}-11.08 Z_{2}+4.51 Z_{3}-6.74 Z_{1}^{2}-11.27 Z_{2}^{2}-1.73 Z_{3}^{2}+5.10 Z_{1} Z_{2}+ \\
0.42 Z_{1} Z_{3}-7.21 Z_{2} Z_{3} ; \\
\rho=1.94-0.135 Z_{1}+0.015 Z_{2}+0.043 Z_{3}+0.013 Z_{1}^{2}+0.012 Z_{2}^{2}+0.002 Z_{3}^{2}+ \\
0.053 Z_{1} Z_{2}-0.024 Z_{1} Z_{3}-0.046 Z_{2} Z_{3} ; \\
K_{s}=0.58+0.02 Z_{1}+0.05 Z_{1}^{2}+0.13 Z_{2}^{2}+0.08 Z_{3}^{2}+0.04 Z_{1} Z_{2}+0.01 Z_{1} Z_{3}+ \\
0.09 Z_{2} Z_{3} ; \\
W_{m}=12.94+3.39 Z_{1}-0.34 Z_{2}-1.45 Z_{3}-0.57 Z_{1}^{2}-0.14 Z_{2}^{2}+0.01 Z_{3}^{2}-0.46 Z_{1} Z_{2}- \\
0.26 Z_{1} Z_{3}+0.39 Z_{2} Z_{3} .
\end{gathered}
$$

The value of the coefficient $b_{0}$ confirms the analysis of experimental data. An increase in the content of lime dust in the compositions of the molding sand (coefficient $b_{1}$ ) contributes to an increase in strength characteristics and a decrease in the average density of the material; however, it significantly increases the water absorption by weight and reduces the thickness of the carbonized layer of the samples, reducing their water resistance. To a large extent, the formation of the carbonate structure of the material of the experimental samples, which can be indirectly judged by the thickness of the carbonized layer, depends on the initial water content of the molding mixtures, $Z_{2}$ (coefficient $b_{2}$ ). With an increase in water content in the system, the carbonized layer of the samples decreases and the compressive strength decreases, and the decrease in strength is significant $\left(b_{2}=-11.08\right)$. The growth in pressing pressure, factor $Z_{3}$ (coefficient $b_{3}$ ), increases the average density of the samples, their $\mathrm{R}_{\mathrm{c}}$ and reduces $\mathrm{W}_{\mathrm{m}}$. Moreover, with an increase in the density of the structure, the thickness of the carbonized layer and the water resistance of the test samples decrease.

\section{Conclusions}

An analysis of equations 2-5 made it possible to establish that the optimal molding pressure range for pressing, which allows obtaining maximum compressive strength (more than 40 $\mathrm{MPa}$ ), is in the range from 25 to $30 \mathrm{MPa}$. Moreover, to obtain such strength indicators, the optimal content of lime dust in raw materials is in the range of $35-40 \%$ wt. when the water content of the mixture is $6-7 \%$ wt. The carbonized material obtained with the indicated technological parameters will have an average density of $1.95-2.0 \mathrm{~g} \cdot \mathrm{cm}^{-3}$ and water absorption by weight of not more than $12 \%$. The water resistance of the material by softening coefficient will be $0.65-0.75$. It was found that $\mathrm{K}_{\mathrm{s}}$ depends on the thickness of the carbonized layer, the value of which increases with increasing thickness of the layer. Accordingly, an increase in carbonation time (this study was taking 3 hours as an example) will growth the water resistance of the carbonized material on the basis of the investigated secondary raw materials. Thus, the data obtained make it possible to consider the possibility of obtaining high-quality building products with physic-mechanical, physicochemical, hydro physical, and other properties sufficient for building materials by means of semi-dry pressing in a short time period based on calcareous dust and fine limestone waste.

The study was conducted with the financial support of the intra-university grant of V.I. Vernadsky Crimean Federal University. 


\section{References}

1. European Commission. A strategic long-term vision for a prosperous, modern, competitive and climate-neutral EU economy. URL: https://ec.europa.eu/clima/policies/strategies/2050_en

2. K. Scrivener, V. John, E. Gartner Cem. Concr. Res. 114, 2-26 (2018)

3. P. Humbert, J. Castro-Gomes J. Clean. Prod. 208, 448-457 (2019)

4. E. Gartner Cem. Concr. Res. 34, 1489-1498 (2004)

5. P. De Silva, L. Bucea, D. Moorehead, V. Sirivivatnanon Cem. Concr. Comp. 28, 613620 (2006)

6. T.A. Plekhanova, J. Kerieneb, A. Gailiusb, G.I. Yakovlev Constr. and Build. Mater.21, 1833-1838 (2007)

7. M. Liska, A. Al-Tabbaa Construct. Build. Mater. 22, 1789-1797 (2008)

8. D. Kannan Int. J. Prod. Econ. 195, 391-418 (2018)

9. R. Maddalena, J. Roberts, A. Hamilton J. Clean. Prod. 186, 933-942 (2018)

10. R. Kajaste, M. Hurme J. Clean. Prod. 112, 4041-4052 (2016)

11. P. Humbert, J. Castro-Gomes, H. Savastano Construct. Build. Mater. 210, 413-421 (2019)

12. Z. Ghouleh, R. Guthrie, Y. Shao Construct. Build. Mater. 99, 175-183 (2015)

13. H. Huang et al. J. Clean. Prod. 241, 118359 (2019)

14. Z. Ghouleh, R. Guthrie, Y. Shao J. $\mathrm{CO}_{2}$ Utiliz. 18, 125-138 (2017).

15. T. Bakhtina, N. Lyubomirskiy, A. Bakhtin Mater. Today: Proceed. 19, 1998-2004 (2019)

16. T. Bakhtina, N. Lyubomirskiy, A. Bakhtin E3S Web of Conferences 97, 02024 (2019)

17. N. Lyubomirskiy, T. Bakhtina, A. Bakhtin, S. Fedorkin Mater. Scien. Forum 974, 187$194(2020)$

18. N. Lyubomirskiy, A. Bakhtin, T. Bakhtina IOP Conf. Series: Mater. Sci. and Engin. 365, 032032 (2018)

19. C. Unluer, A. Al-Tabbaa, Cem. Concr. Res. 54, 87-97 (2013)

20. Y. Yi, M. Liska, A. Al-Tabbaa. Adv. Cem. Res. 26, 114-122 (2014)

21. C. Unluer, A. Al-Tabbaa Constr. Build. Mater. 94, 629-643 (2015)

22. N. Lyubomirskiy, A. Bakhtin, T. Bakhtina IOP Conf. Series: Mater. Sci. and Engin. 463, 032065 (2018)

23. V. Gavrish, T. Chayka, G. Baranov, S. Fedorova, O. Gavrish Mater. Today: Proceed. 19, 1961-1964 (2019)

24. S. Fedorova, L. Nichkova, G. Baranov, Ju. Shagova Mater. Today: Proceed. 19, 19411944 (2019)

25. N. Lyubomirskiy, S. Fedorkin, T. Loktionova, A. Bakhtin, Ukraine Patent 28051 (2006) 